\title{
EFFECT OF DILUTE ACID PRETREATMENT OF VEGETABLE WASTE ON SUGAR PRODUCTION AND INHIBITOR FORMATION
}

\author{
Denistira Fazlur Rahman I Hakun Wirawasista Aparamarta I Arief Widjaja*
}

Dept. of Chemical Engineering, Institut Teknologi Sepuluh Nopember, Surabaya, Indonesia

\section{Correspondence}

*Arief Widjaja, Dept. of Chemical Engineering, Institut Teknologi Sepuluh Nopember, Surabaya, Indonesia. Email: arief_w@chem-eng.its.ac.id

\section{Present Address}

Gedung Teknik Kimia, Kampus ITS Sukolilo, Surabaya 60111, Indonesia

\begin{abstract}
Vegetable waste is an organic waste with high cellulose and hemicellulose and low lignin content. The cellulose and hemicellulose chains can be broken down by pretreatment using sulfuric acid to obtain reducing sugar. To avoid the formation of degradation products that have the potential as inhibitor compounds, the temperature of the pretreatment operation was carried out at 121 and 125 for 60 minutes with sulfuric acid concentrations varying from $0.5 \%$ to $1.5 \%(\mathrm{v} / \mathrm{v})$. The solid and liquid ratio $(\mathrm{S} / \mathrm{L})$ was $5 \%(\mathrm{w} / \mathrm{v})$. From the experiments, the highest total reducing sugars of 7.068 $\mathrm{g} / \mathrm{L}$ was obtained by pretreatment conditions at 121 for 60 minutes with a sulfuric acid concentration of $1 \%(\mathrm{v} / \mathrm{v})$. Meanwhile, the lowest total reducing sugar of 2.764 $\mathrm{g} / \mathrm{L}$ was produced during the pretreatment operating conditions at 125 for 60 minutes with a sulfuric acid concentration of $1 \%(\mathrm{v} / \mathrm{v})$. Under the present experimental condition, it was found that only a low level of degradation product was formed, which ensures excellent performance of bacterial growth in the subsequent fermentation process.
\end{abstract}

\section{KEYWORDS:}

Dilute Sulfuric Acid, Inhibitor Compounds, Sugar Production, Vegetable Waste

\section{1 | INTRODUCTION}

Waste has become one of the essential issues for every country in the world. On the other hand, the availability of fossil energy has decreased due to an annual increase in energy consumption. Conversion of waste, especially organic waste, into renewable energy is the best solution for the issues. Hydrogen is a renewable energy that has high energy content and is environmentally friendly, which can be used for electricity generation and transportation in the future ${ }^{[1}$. In addition to chemical processes, hydrogen can be produced through biological processes, namely fermentation ${ }^{2]}$. 
One type of organic waste that has the potential to be converted to hydrogen is a vegetable waste because it has high cellulose and hemicellulose content with small lignin content ${ }^{3}$. Hydrolysis, cellulose, and hemicellulose, can be converted into monomeric sugar compounds, such as glucose, xylose, arabinose, and galactose ${ }^{4}$. The compounds can be used as a substrate in the hydrogen fermentation process. However, from the studies that have been conducted, no one has carried out further studies about the pretreatment method to increase sugar concentration through the hydrolysis of cellulose and hemicellulose from vegetable waste. The higher the concentration of sugar produced will potentially increase hydrogen production through a fermentation process.

Many methods can be applied to break down the cellulose and hemicellulose chains containing a matrix that is quite complex. Physicochemical pretreatment is a method that has been widely used to break down the complex chains. Some physicochemical methods such as pretreatment using alkaline solvents such as sodium hydroxide and using acid solvents such as sulfuric acid, acetic acid have been widely applied. Physicochemical pretreatment using diluted sulfuric acid is the most commonly employed method because it is simple, relatively cheap, and produces high sugar yields ${ }^{5}$ [6. The strength of the cellulose and hemicellulose chain has certain stability in acidic and thermal conditions. Beyond this limit, the chain breaks down and becomes very soluble in acid that cellulose and hemicellulose could be converted into sugar monomers, which are more easily extracted. In this case, pretreatment with dilute sulfuric acid is the appropriate option to achieve this condition. However, operating conditions such as operating time, operating temperature, acid concentration, and (S/L) ratio of biomass much determined the effectiveness of this method ${ }^{7[8]}$. If the acid concentration and temperature used are higher with the longer duration of pretreatment, 5hydroxymethylfurfural (HMF) will be formed from glucose degradation, and so does furfural, acetic acid, and formic acid formed from xylose degradation $9[10$. These compounds will inhibit the metabolic process of microorganisms in fermentation, which causes a lower ability of bacteria to utilize sugar, resulting in lower hydrogen production. Each bacterium, however, has a different tolerance limit to the number of inhibitor compounds during the fermentation process 8 .

This study aimed to investigate the effect of dilute acid pretreatment of vegetable waste on sugar production and inhibitor formation using sulfuric acid solvents. The operating conditions of pretreatment, such as temperature, time, and the concentration of sulfuric acid, were evaluated to obtain the highest reducing sugar yield. Besides, the formation of degradation products from the treatment process was also assessed.

\section{2 | MATERIAL AND METHOD}

\section{1 | Vegetable Waste}

Vegetable waste used in this study was collected from the Keputran market, a local market in Surabaya, Indonesia. The vegetable waste was dried in an oven at temperature 60 for 3-4 d. Then, the vegetable was chopped into small pieces less than $5 \mathrm{~mm}$ in length and width approximately.

\section{2 | Dilute Acid Pretreatment}

The dilute sulfuric acid pretreatment was performed using a $250 \mathrm{ml}$ glass reactor and $150 \mathrm{ml}$ working volume. The dried sample was pretreated in $0,5-1,5 \% \mathrm{H} 2 \mathrm{SO} 4(\mathrm{v} / \mathrm{v})$ at $5 \%(\mathrm{w} / \mathrm{v}) \mathrm{S} / \mathrm{L}$ ratio. The pretreatment process was carried out in an autoclave at 121 and 125 for 30 and 60 minutes After the reaction was complete, the reactor was cooled to room temperature. The solid and liquid components were filtered using an ashless filter paper (Whatman, UK). The liquid fraction (hydrolysate) was stored at temperature 4 for analysis.

\section{3 | Analytical method}

The reducing sugar of the liquid fraction obtained from dilute sulfuric acid pretreatment was analyzed using the dinitro salicylic acid (DNS) method 11 . VFAs ( acetic acid, butyric acid, propionic acid ) and inhibitory compounds such as 5-HMF and Furfural were analyzed by GC-FID (GC-2010 Plus Shimadzu, Kyoto, Japan). The pH of dilute sulfuric acid pretreatment hydrolysate was measured by a portable $\mathrm{pH}$ meter ( $\mathrm{pH} 5+$ Eutech, Ayer Rajah Crescent, Singapore). Hydrogen from the dark and photo fermentation process was analyzed using GC-TCD (GC-2010 Plus Shimadzu, Kyoto, Japan). 


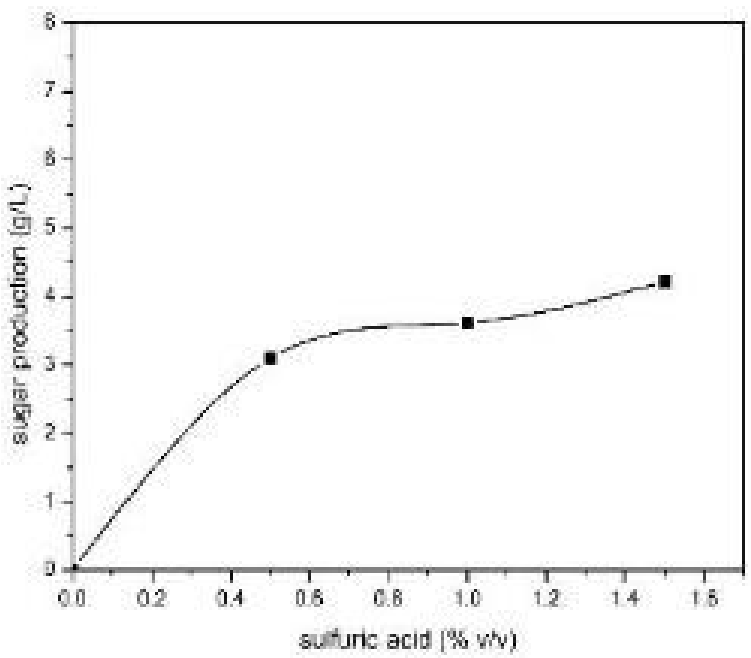

FIGURE 1 Sugar reduction effect of sulfuric acid on the concentration at 121 for 30 minutes.

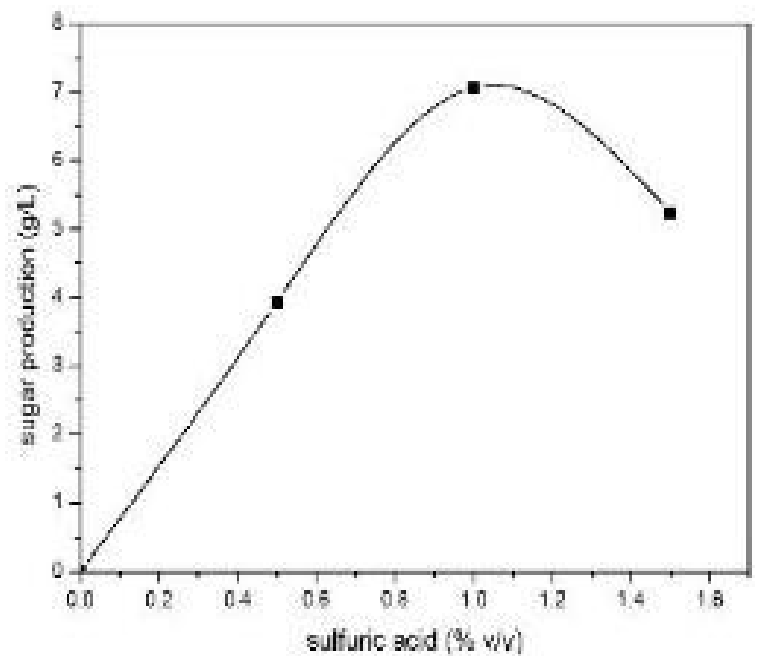

FIGURE 2 Sugar reduction effect of sulfuric acid on the concentration at 121 for 60 minutes.

\section{3 | RESULTS AND DISCUSSION}

\section{1 | Dilute Acid Pretreatment}

The pretreatment process using dilute sulfuric acid was carried out at 121 and 125 for 60 minutes in an autoclave. The selection of the operating temperature was aimed to minimize the formation of degradation products from the hydrolysis of cellulose and hemicellulose and compounds that have potency as inhibitors in the fermentation process. Rasmussen et al. ${ }^{[12]}$ reported that the potency for the formation of degradation products and inhibitor compounds would appear when the pretreatment operating temperature was more than 150 . In several studies of dilute sulfuric acid, the operating conditions chosen to maximize monomer sugar production and minimize the formation of inhibitor components were by 1) the use of low sulfuric acid concentrations, below $2 \%(\mathrm{v} / \mathrm{v})$ at high operating temperatures above 150 with over 60 minutes ${ }^{[13]}$ or 2) the use of high acid concentrations above $2 \%(\mathrm{v} / \mathrm{v})$ at operating temperatures below 150 for 60 minutes ${ }^{8}$. However, the use of low sulfuric acid concentrations with low pretreatment temperatures will be an interesting topic that will be discussed in this study.

\section{2 | Reducing Sugar}

Figure 1 and Figure 2 show the sugar produced by dilute acid pretreatment at 121 for 30 and 60 minutes. The highest reducing sugar of $7.163 \mathrm{~g} / \mathrm{L}$ was obtained with $1 \%$ sulfuric acid for 60 minutes of pretreatment time. After reaching the optimum point, the reduction of sugar was continued to decrease when sulfuric acid was continued to increase. Likewise, with experiments at 125, as shown in fFgure 3 and Figure 4 , the highest reducing sugar concentration of $4.2601 \mathrm{~g} / \mathrm{L}$ resulted from the addition of $1 \%$ sulfuric acid for 60 minutes. When using $0.5 \%$ sulfuric acid, the sugar concentration obtained was less than using one sulfuric acid. i.e. $2.764 \mathrm{~g} / \mathrm{L}$. It can be seen that the effect of using higher concentrations and also higher temperatures would cause reducing sugar production to decrease. The trendline of the product that formed is the same as research conducted by Kim et al. ${ }^{[13]}$ using different acid, acetic acid at concentrations of $0 \%$ to $0.8 \%(\mathrm{v} / \mathrm{v})$ when it reached the optimum level, the high concentration of acid used, the sugar production was decreased even with different operating temperatures. On the other hand, with the pretreatment time of 30 minutes, reducing sugar production was continued to increase with the higher concentration of sulfuric acid used both at 121 and 125, as shown in Figure 1 and Figure 3 At a pretreatment of 121 for 30 minutes, the highest reducing sugar was obtained at $4.222 \mathrm{~g} / \mathrm{L}$ with a concentration of $1,5 \% \mathrm{v} / \mathrm{v}$ sulfuric acid. Whereas in the pretreatment temperature of 125 for 30 minutes, the highest reducing sugar was sugar can not be reached an optimum point. It was caused by an incomplete hydrolysis process of cellulose and hemicellulose into monomeric sugar components. In other words, there were still some cellulose and hemicellulose that had not been hydrolyzed yet. 


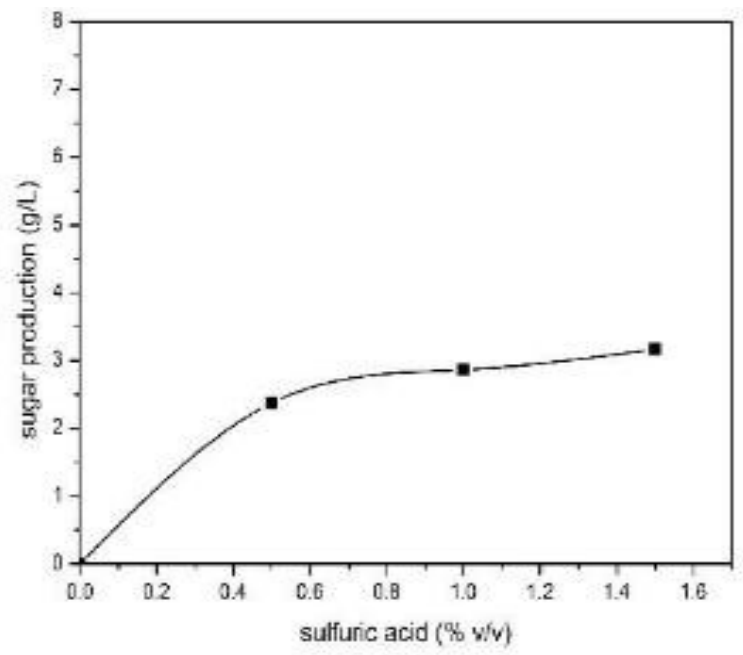

FIGURE 3 Sugar reduction effect of sulfuric acid on the concentration at 125 for30 minutes.

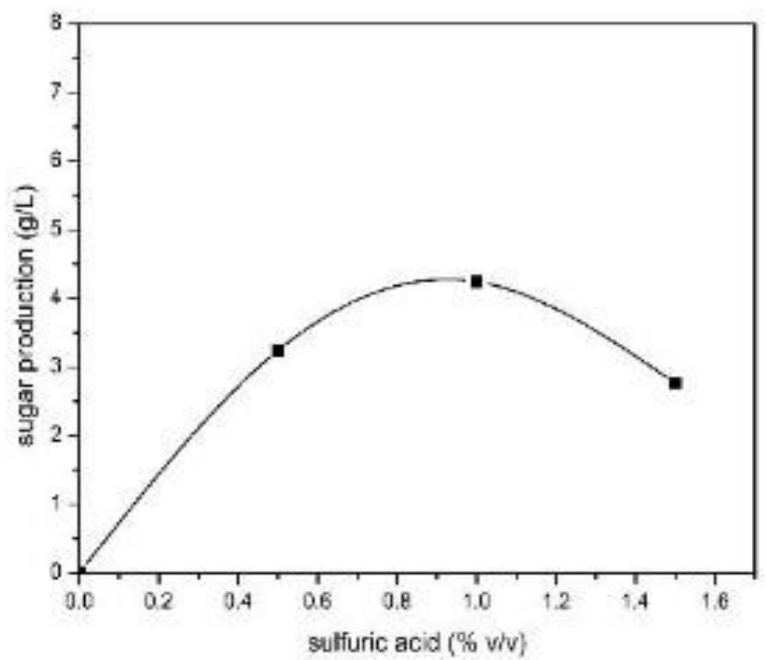

FIGURE 4 Sugar reduction effect of sulfuric acid on the concentration at 125 for 60 minutes.

Meanwhile, the use of sulfuric acid with a concentration of $1.5 \%(\mathrm{v} / \mathrm{v})$ decreased the sugar concentration. This may due to the majority of the sugar from hydrolysis has been degraded to other compounds such as acetic acid, ethanol, furfural, and 5 -HMF [4. This caused the sugar concentration obtained becomes smaller compared to pretreatment using $1 \%$ sulfuric acid. Rajan and Carrier ${ }^{[14]}$ reported the phenomenon of reducing sugar that continued to decline caused by the degradation process of reducing sugars to acetic acid, 5-HMF, and furfural. In high temperatures, water was able to act as both acid and base catalysts that glucose decomposed to 5-HMF by reaction with an acid catalyst and lactic acid from the reaction with a base catalyst even without a catalyst ${ }^{[13]}$.

Moreover, under a longer time and higher concentration of sulfuric acid, furfural was able to be degraded to formic acid and levulinic acid ${ }^{[15]}$. Furfural is produced from the results of xylose and arabinose degradation ${ }^{[12]}$. The hydrogen ion produced from the breakdown of cellulose and hemicellulose would become a sugar monomer which dissolves in the hydrolyzate.

However, at the same time, hydrogen ions also bound to the hydroxyl sugar group so that dehydration occurred. Thus, it increased furfural concentrations (Islam et al., 2017). The acetic acid is formed from the hydrolysis process of acetyl groups in hemicellulose. It is in line with the decrease in xylose production. In the study conducted by (Guo et al., 2008) more than $90 \%$ of acetyl groups were converted to acetic acid on the severity factor above 2.0 for all raw materials. Acetic acid also would not be decomposed into other compounds even though the severity factor increases (Guo et al., 2008). The concentration of $1 \mathrm{~g} / \mathrm{L}$, acetic acid, would inhibit clostridial species metabolism, in which the bacteria are the primary producers of hydrogen in dark fermentation (Monlau et al., 2013). However, for the biogas fermentation process, acetic acid would not inhibit bacterial metabolism because it can be used as a precursor for biogas formation (Zhang et al., 2011). According to Zhu et al. [16], a higher concentration of sulfuric acid, longer pretreatment time, and higher pretreatment temperature, the sugar degradation process sufficient. The scheme of formation of degradation products from the hydrolysis process of cellulose and hemicellulose can be seen in Figure 5 The production of acetic acid in this present study was shown in Figure 6 and Figure 7

\section{3 | Degradation Products}

The formation of furfural in the present study was shown in Figure 8 and Figure 9 The highest furfural concentration was formed at a temperature of 125 , with a $1.5 \%$ concentration of sulfuric acid, which was equal to $0.0253 \mathrm{~g} / \mathrm{L}$. While the lowest furfural concentration was formed at 121 with a concentration of $0.5 \%$, sulfuric acid was equivalent to $0,0024 \mathrm{~g} / \mathrm{L}$. The furfural concentration would be continued to increase with increasing temperature and the concentration of sulfuric acid used, as shown in Figure 4 In the fermentation process of hydrogen, furfural and 5-HMF are inhibitor compounds were able to inhibit the metabolic process of bacteria that will reduce the ability of bacteria to produce hydrogen. Both of these compounds will inhibit 


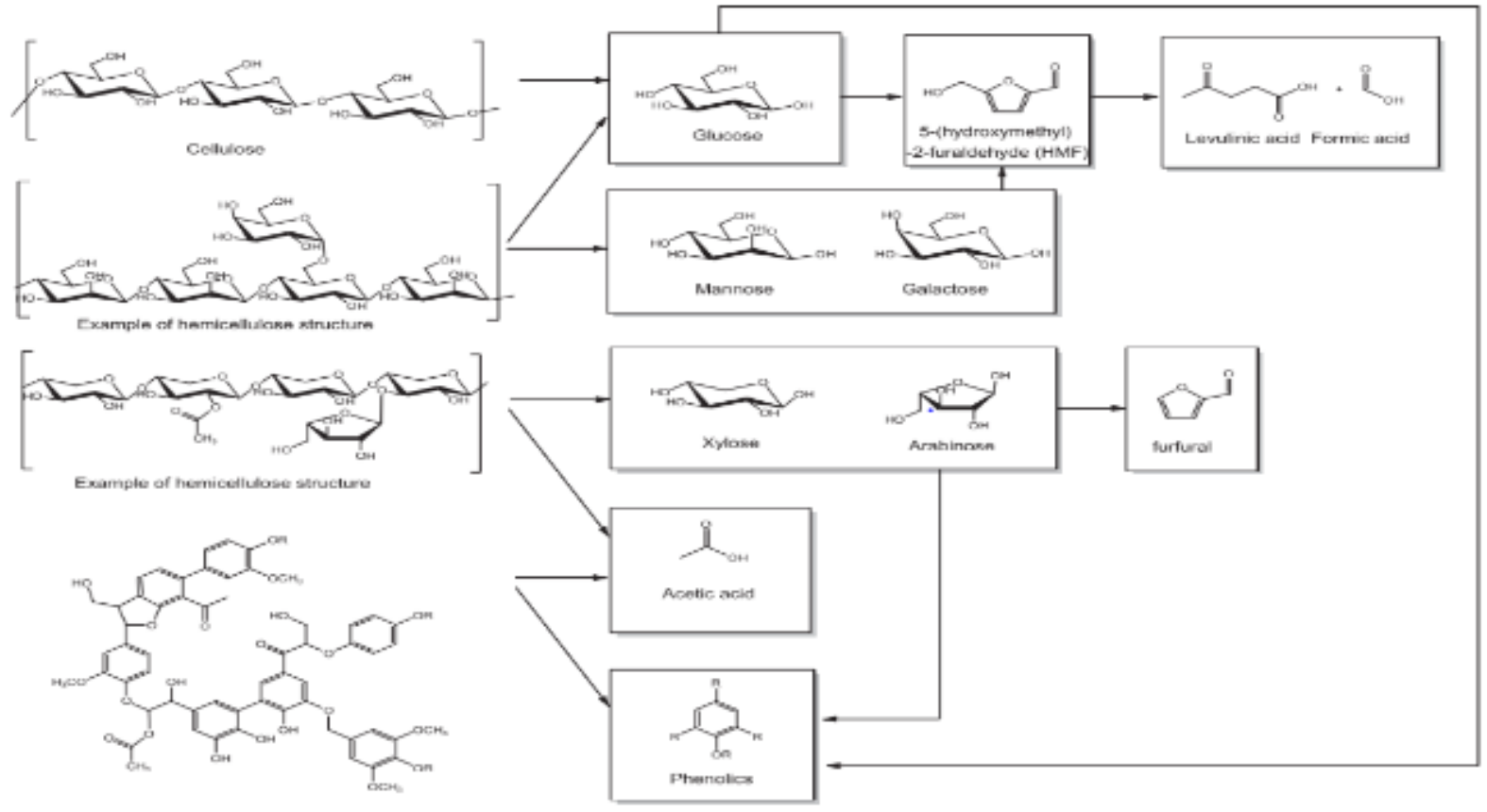

FIGURE 5 Scheme of formation of degradation products from the hydrolysis process of cellulose and hemicellulose.

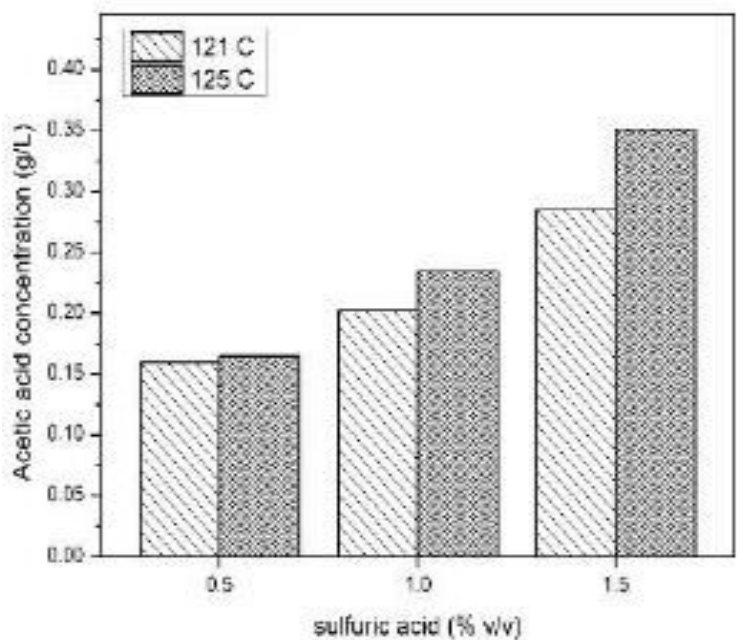

FIGURE 6 Effect of sulfuric acid on the acetic acid concentration after 30 minutes.

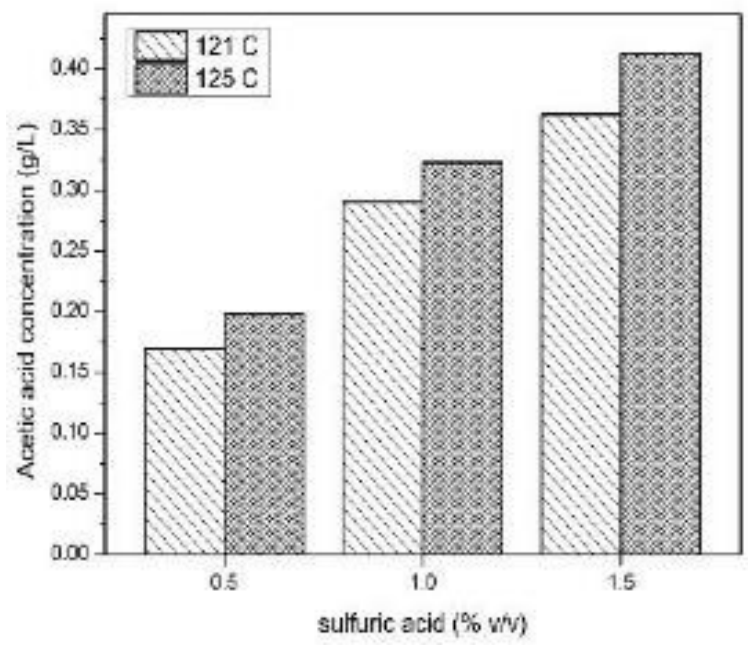

FIGURE 7 Effect of sulfuric acid on the acetic acid concentration after 60 minutes.

bacterial growth when, in the cytoplasm, the concentration of microorganisms reached up to $1 \mathrm{~g} / \mathrm{L}$, which caused death in microorganisms ${ }^{[8]}$.

In the study conducted by Kumar et al. [17], with a 5-HMF concentration of $0.59 \mathrm{~g} / \mathrm{L}$, it would be able to influence bacterial growth for hydrogen production. When compared to furfural, the molecular size of 5-HMF is smaller than that of a furfural molecule, making 5-HMF more toxic to microorganisms. The larger size of furfural would be more challenging to enter into microorganisms. In addition, furfural contained in media with anaerobic conditions will be reduced to furfuryl alcohol. These two compounds would undoubtedly inhibit the metabolism of micro-organisms for hydrogen production [5]. 


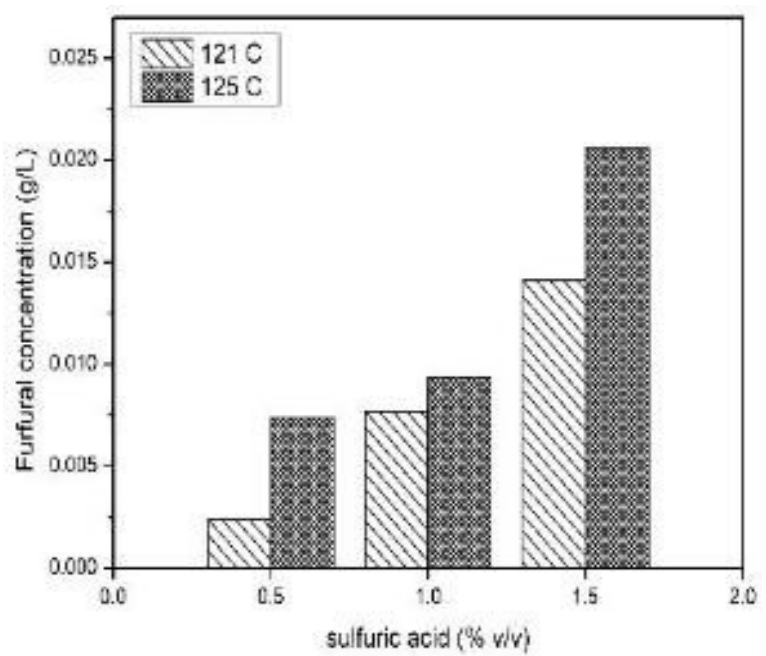

FIGURE 8 Effect of sulfuric acid on the furfural concentration after 30 minutes.

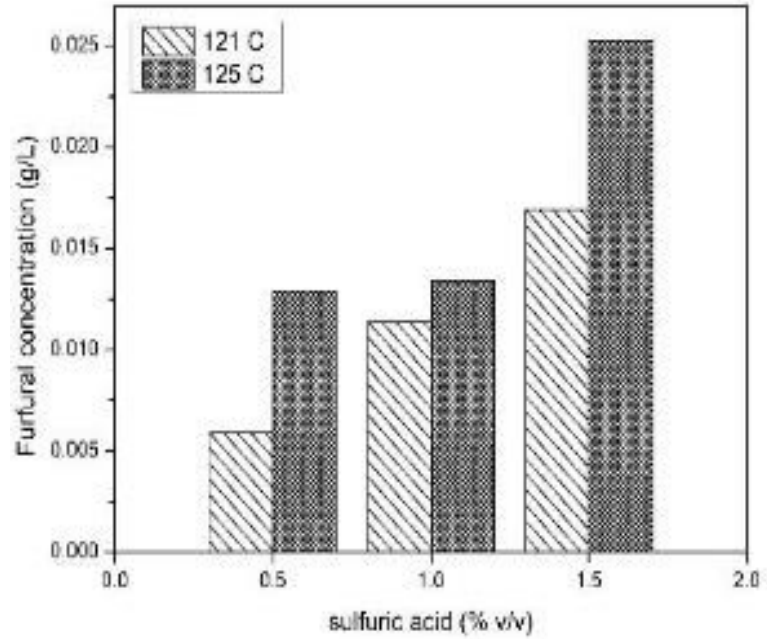

FIGURE 9 Effect of sulfuric acid on the furfural concentration after 60 minutes.

From the study conducted by Gonzales et al. ${ }^{[8]}$, using sulfuric acid of $5 \%(\mathrm{v} / \mathrm{v})$ at 121 for 90 minutes, the resulting furfural concentration reached $12,47 \mathrm{~g} / \mathrm{L}$. This study also discussed hydrogen production using a substrate with a sugar concentration of $5 \mathrm{~g} / \mathrm{L}$ and a furfural concentration of $12.47 \mathrm{~g} / \mathrm{L}$ produced hydrogen yields of $1.18 \mathrm{~mol} \mathrm{H} 2 / \mathrm{mol}$ glucose. Compared with the present study, the hydrolysate from dilute sulfuric acid pretreatment with a sugar concentration of 7,163 g/L and the furfural concentration of $0,045 \mathrm{~g} / \mathrm{L}$ can be used and seems suitable for hydrogen fermentation. In a different study reported by Islam et al. ${ }^{[18]}$, using liquid products from dark fermentation to be pretreated using $1.5 \% \mathrm{v} / \mathrm{v}$ sulfuric acid at 120 for 60 minutes could increase hydrogen production $76 \%$. The selection of operating conditions such as the temperature and concentration of sulfuric acid used also has a positive impact on the production of reducing sugar with small concentrations of inhibitor compounds. The strategy for increasing the amount of sugar produced can also be done by increasing the S/L ratio used. Generally, the S/L ratio used is $5 \%-10 \%(\mathrm{w} / \mathrm{v})$. Where the selection is based on the comparison of the proportion of lignin, cellulose, and hemicellulose content in the material to the concentration of sulfuric acid to be used.

\section{4 | CONCLUSION}

Pretreatment of vegetable waste using dilute sulfuric acid with a concentration of $1 \%$ at 121 for 60 minutes produced high reducing sugars. Only a low concentration of degradation products i.e., furfural, that has the potency as an inhibitor, was formed from pretreatment. The hydrolyzate from the pretreatment is suitable as the substrate for hydrogen fermentation because of high reducing sugar and low content of inhibitor compounds. Moreover, the possibility of increasing reducing sugars by increasing the S/Lmai ratio can be considered. The results of the experiments show that the higher the temperature and concentration of sulfuric acid used, the higher the potency for the formation of degradation products that will become inhibitor compounds in the fermentation process.

\section{5 | ACKNOWLEDGMENT}

The authors thank The Institution of Research and Community Service, Institut Teknologi Sepuluh Nopember and Laboratory of Biochemical Technology, Chemical Engineering Department. 


\section{References}

1. Saidi R, Liebgott PP, Hamdi M, Auria R, Bouallagui H. Enhancement of Fermentative Hydrogen Production by Thermotoga Maritima Through Hyperthermophilic Anaerobic Co-Digestion of Fruit-Vegetable and Fish Wastes. International Journal of Hydrogen Energy 2018;43(52):23168-23177.

2. Chookaew T, O-thong S, Prasertsan P. Biohydrogen Production from Crude Glycerol by Two Stage of Dark and Photo Fermentation. International Journal of Hydrogen Energy 2015;40(24):7433-7438.

3. Singh A, Kuila A, Adak S, Bishai M, Banerjee R. Utilization of Vegetable Wastes for Bioenergy Generation. Agricultural Research 2012;1(3):213-222.

4. Kapoor M, Raj T, Vijayaraj M, Chopra A, Gupta RP, Tuli DK, et al. Structural Features of Dilute Acid, Steam Exploded, and Alkali Pretreated Mustard Stalk and Their Impact on Enzymatic Hydrolysis. Carbohydrate Polymers 2015;124:265-273. http://dx.doi.org/10.1016/j.carbpol.2015.02.044

5. Gonzales RR, Sivagurunathan P, Parthiban A, Kim SH. Optimization of Substrate Concentration of Dilute Acid Hydrolyzate of lignocellulosic Biomass in Batch Hydrogen Production. International Biodeterioration and Biodegradation 2016;113:22_ 27.

6. Rolly R, Kumar G, Sivagurunathan P, Kim Sh. Enhancement of Hydrogen Production by Optimization of pH Adjustment and Separation Conditions Following Dilute Acid Pretreatment of Lignocellulosic Biomass. International Journal of Hydrogen Energy 2017;42(45):27502-27511.

7. Park JH, Cheon HC, Yoon JJ, Park HD, Kim SH. Optimization of Batch Dilute-Acid Hydrolysis for Biohydrogen Production from Red Algal Biomass. International Journal of Hydrogen Energy 2013;38(14):6130-6136.

8. Gonzales RR, Sivagurunathan P, Kim SH. Effect of Severity on Dilute Acid Pretreatment of Lignocellulosic Biomass and the Following Hydrogen Fermentation. International Journal of Hydrogen Energy 2016;41(46):21678-21684.

9. Dussan KJ, Silva DDV, Moraes EJC, Arruda PV, Felipe MGA. Dilute-Acid Hydrolysis of Cellulose to Glucose from Sugarcane Bagasse. Chemical Engineering Transactions 2014;38:433-438.

10. Jin F, Zhou Z, Moriya T, Kishida H, Higashijima H, Enomoto H. Controlling Hydrothermal Reaction Pathways to Improve Acetic Acid Production from Carbohydrate Biomass. Environmental Science and Technology 2005;39(6):1893-1902.

11. Miller GL. Use of Dinitrosalicylic Acid Reagent for Determination of Reducing Sugar. Analytical Chemistry 1959;31(3):426-428.

12. Rasmussen H, Sorensen HR, Meyer AS. Formation of Degradation Compounds from Lignocellulosic Biomass in the Biorefinery: Sugar Reaction Mechanisms. Carbohydrate Research 2014;385:45-57.

13. Kim YS, Jang JY, Park SJ, Um BH. Dilute Sulfuric Acid Fractionation of Korean Food Waste for Ethanol and Lactic Acid Production by Yeast. Waste Management 2018;74:231-240.

14. Rajan K, Carrier DJ. Effect of Dilute Acid Pretreatment Conditions and Washing on the Production of Inhibitors and on Recovery of Sugars During Wheat Straw Enzymatic Hydrolysis. Biomass and Bioenergy 2014;62:222-227.

15. Jonsson LJ, Martin C. Pretreatment of lignocellulose : Formation of inhibitory by-Products and Strategies for Minimizing Their Effects. Bioresource Technology 2016;199:103-112.

16. Zhu S, Huang W, Huang W, Wang K, Chen Q, Wu Y. Pretreatment of Rice Straw for Ethanol Production Dilute Sulfuric Acid and Sulfomethylation Reagent. Applied Energy 2015;154:190-196.

17. Kumar G, Cheon Hc, Kim Sh. Effects of 5 Hydromethylfurfural Levulinic Acid and Formic Acid Pretreatment by Products of Biomass, on Fermentative H 2 Production from Glucose and Galactose. International Journal of Hydrogen Energy 2014;39(30):16885-16890. 
18. Md Saiful Islam, Chen Guo CZL. Enhanced Hydrogen and Volatile Fatty acid Production from Sweet Sorghum Stalks by Two-Steps Dark Fermentation with Dilute Acid Treatment in Between. International Journal of Hydrogen Energy 2018;43(2):659-666.

How to cite this article: Rahman D.F, Aparamarta H.W., Widjaya A., (2020), Effect of Dilute Acid Pretreatment of Vegetable Waste on Sugar Production and Inhibitor Formation, IPTEK The Journal of Technology and Science, 31(1):75-82. 